\title{
THE ANNUAL MEETING IN ATLANTIC CITY AND PRINCETON
}

The thirty-ninth Annual Meeting of the American Mathematical Society was held at Atlantic City and Princeton, New Jersey, from Tuesday to Friday, December 27-30, 1932. The sessions of the Society, Tuesday to Thursday inclusive, were held in the Hotel Morton in Atlantic City; the events on Friday took place at Princeton University. The arrangements as made by the committee, of which Professor J. R. Kline was chairman, were excellent and the meeting proved to be exceptionally interesting and pleasant.

The meeting opened on Tuesday morning with a joint session of the Society, Sections A and K of the American Association for the Advancement of Science, and the Econometric Society. At this session, which was devoted to mathematical statistics, Dr. W. A. Shewhart delivered an invited address on Probability as a basis for action. This was discussed by Professors E. V. Huntington and Harold Hotelling. Tuesday afternoon and Wednesday morning were devoted to sessions of the Mathematical Association of America.

A meeting of the Board of Trustees was held on Tuesday afternoon. The Council met on Wednesday afternoon and on Thursday evening.

Tuesday evening and Thursday morning were devoted to sectional sessions. On Wednesday afternoon, at a joint session with Section A of the A.A.A.S. and the Mathematical Association of America, Dean L. P. Eisenhart delivered his retiring address as President of the Society, entitled Some recent developments in differential geometry, which will appear in an early issue of this Bulletin; and Professor E. R. Hedrick, as retiring Vice-President of Section A, spoke on Tendencies in the logic of mathematics; this paper will appear in Science.

The annual dinner of the mathematical organizations on Wednesday evening was held in the Hotel Morton, 235 being present and President Eisenhart acting as toastmaster. Professor Oswald Veblen spoke on the new Institute for Advanced Study; Professor Virgil Snyder on the demise of the International Mathematical Union; Professor R. C. Archibald read ex- 
tracts from a letter about the new congruence machine invented by Dr. D. H. Lehmer; and the incoming presidents, Professor A. B. Coble of the Society and Professor Arnold Dresden of the Mathematical Association, spoke briefly.

The annual business meeting on Thursday afternoon was followed by a general session. Later in the afternoon the tenth Josiah Willard Gibbs lecture entitled Thermodynamics and relativity was delivered by Professor R. C. Tolman of the California Institute of Technology. This brilliant paper will be printed both in this Bulletin and in Science.

Friday was spent at Princeton University, the late morning being devoted to an inspection of the new mathematical building, the Henry Burchard Fine Memorial Hall. In the afternoon there was a symposium on Application of the operational calculus to mechanics, participated in by Professors J. von Neumann, G. D. Birkhoff, and Eberhard Hopf. After the session, tea was served by the ladies of the department.

The attendance included the following two hundred twentyfour members :

C. R. Adams, V. W. Adkisson, R. P. Agnew, Beatrice Aitchison, J. W. Alexander, R. C. Archibald, H. E. Arnold, C. S. Atchison, Frank Ayres, M. J. Babb, R. W. Babcock, C. L. Bacon, N. H. Ball, E. F. Beckenbach, E. R. Beckwith, A. A. Bennett, G. D. Birkhoff, A. H. Black, H. L. Black, Archie Blake, Henry Blumberg, Joseph Bowden, J. W. Bower, N. R. Bryan, R. W. Burgess, J. H. Bushey, W. H. Bussey, W. E. Byrne, S. S. Cairns, W. D. Cairns, R. H. Cameron, B. H. Camp, P. A. Caris, M. E. Carlen, Leonard Carlitz, W. B. Carver, G. G. Chambers, W. F. Cheney, Alonzo Church, J. M. Clarkson, A. B. Coble, Abraham Cohen, J. B. Coleman, T. F. Cope, L. P. Copeland, C. H. Currier, E. H. Cutler, Tobias Dantzig, H. T. Davis, F. F. Decker, M. F. Deuring, C. E. Dimick, H. A. DoBell, J. L. Doob, J. L. Dorroh, B. F. Dostal, Jesse Douglas, Arnold Dresden, L. A. Dye, Paul Eberhart, L. P. Eisenhart, H. T. Engstrom, G. C. Evans, G. W. Evans, H. S. Everett, F. J. Feinler, E. J. Finan, W. B. Fite, M. M. Flood, C. H. Forsyth, Tomlinson Fort, A. L. Foster, T. C. Fry, A. S. Gale, F. J. Gerst, D. C. Gillespie, Michael Goldberg, H. V. Gummere, R. M. Gut, C. H. Harry, W. L. Hart, G. A. Hedlund, E. R. Hedrick, Robert Henderson, T. R. Hollcroft, Eberhard Hopf, I. O. Horsfall, Harold Hotelling, E. V. Huntington, J. I. Hutchinson, Louis Ingold, M. H. Ingraham, Dunham Jackson, Nathan Jacobson, R. P. Johnson, B. W. Jones, E. R. van Kampen, Ralph Keffer, A. J. Kempner, W. S. Kimball, J. R. Kline, Morris Kline, M. S. Knebelman, P. A. Knedler, H. L. Krall, W. D. Lambert, K. W. Lamson, W. W. Landis, V. V. Latshaw, Solomon Lefschetz, A. M. M. Lehr, D. D. Leib, D. C. Lewis, H. G. Lieber, L. L. Lowenstein, C. I. Lubin, Dorothy McCoy, N. H. McCoy, D. L. McDonough, James McGiffert, L. A. MacColl, C. C. MacDuffee, H. M. MacNeille, H. F. MacNeish, M. H. Martin, A. E. 
Meder, C. W. Mendel, W. M. Miller, H. H. Mitchell, E. C. Molina, E. I. Moody, C. N. Moore, E. M. Morenus, C. B. Morrey, W. K. Morrill, Richard Morris, Marston Morse, G. W. Mullins, F. D. Murnaghan, C. A. Nelson, M. M. Ness, John von Neumann, C. O. Oakley, H. L. Olson, Oystein Ore, L. J. Paradiso, E. D. Pepper, H. B. Phillips, G. B. Price, W. R. Ransom, H. W. Raudenbush, G. E. Raynor, M. S. Rees, C. E. Rhodes, R. G. D. Richardson, D. E. Richmond, H. L. Rietz, J. F. Ritt, H. P. Robertson, L. B. Robinson, S. L. Robinson, W. H. Roever, C. F. Roos, M. F. Rosskopf, F. H. Safford, I. J. Schoenberg, H. E. Schoonmaker, C. E. Seely, Wladimir Seidel, Joseph Seidlin, F. R. Sharpe, I. M. Sheffer, W. A. Shewhart, J. A. Shohat, L. G. Simons, James Singer, L. L. Smail, C. H. Smiley, C. E. Smith, D. E. Smith, T. L. Smith, W. M. Smith, Virgil Snyder, G. Y. Sosnow, A. E. Staniland, E. P. Starke, E. C. Stokes, D. J. Struik, M. M. Sullivan, P. M. Swingle, J. L. Synge, J. D. Tamarkin, J. S. Taylor, M. E. Taylor, E. W. Titt, R. C. Tolman, C. C. Torrance, J. I. Tracey, J. L. Vanderslice, Oswald Veblen, H. E. Wahlert, G. W. Walker, J. L. Walsh, R. M. Walter, J. H. Weaver, Warren Weaver, J. H. M. Wedderburn, D. W. Weeks, F. M. Weida, A. P. Wheeler, H. S. White, Hassler Whitney, G. T. Whyburn, D. V. Widder, Norbert Wiener, A. H. Wilson, C. R. Wilson, E. W. Wilson, W. A. Wilson, R. G. Wood, F. S. Woods, C. H. Yeaton, Oscar Zariski, Leo Zippin.

It was announced that the following persons had been elected to membership in the Society:

Mr. Harold Freeman Archibald, Ohio State University;

Miss Muriel Amanda Bowden, St. Agatha School, New York;

Mr. Alfred H. Clifford, Pasadena;

Dr. Max Friedrich Deuring, Yale University;

Mr. William C. Flaherty, Georgetown University;

Professor John Albert van Groos, Oregon State College;

Professor Dwight Francis Gunder, Colorado Agricultural College;

Dr. Rudolf Max Gut, Yale University;

Professor Winslow N. Hallett, Cedar Crest College;

Mr. Orville G. Harrold, Jr., Stanford University;

Professor Eberhard Hopf, Massachusetts Institute of Technology;

Professor Ralph Hull, State Teachers College, Maryville, Missouri;

Professor William Warren Jones, Kentucky State College;

Mr. Morris Kline, New York University;

Mr. William Irving Miller, University of Pittsburgh;

Professor John von Neumann, Princeton University;

Professor Sylvia Louise Parker, State College, San José, California;

Mr. Victor Perlo, Corona, New York;

Professor Emily Chandler Pixley, St. Francis Xavier College for Women;

Dr. Mildred Marie Sullivan, Harvard University;

As Nominees of Allyn and Bacon: Mr. Ingo Maddaus, University of Michigan; Mr. William Clare Taylor, University of Wisconsin; Mr. Charles Bartlett Tucker, Brown University;

As Nominees of the National Life Insurance Company of the United States of America: Mr. Carroll Parker Brady, University of California at Los Angeles, and Mr. Floyd B. Jones, University of Texas. 
The Secretary announced that the following persons had entered the Society under reciprocity agreements:

Professor Alfred Haar, Franz-Joseph-University, Szeged, Hungary;

Dr. Raymond Edward Alan Christopher Paley, International Research Fellow, Massachusetts Institute of Technology.

The ordinary membership in the Society is now 1882, including 61 nominees of sustaining members and 83 life members. There are also 19 sustaining members. The total attendance of members at all meetings in 1932 was 712 ; the number of papers read was 321 ; the number of members attending at least one meeting 525. A striking feature of the year is that membership held up to previous figures.

At the annual election, which closed on December 29, and at which 251 votes were cast, the following officers were elected:

President, Professor A. B. Coble.

Vice-President, Professor J. W. Alexander.

Associate Secretary, Professor J. R. Kline.

Librarian, Professor R. C. Archibald.

Member of the Editorial Committee of the Bulletin, Professor D. R. Curtiss.

Member of the Editorial Committee of the Transactions, Professor F. R. Sharpe.

Member of the Editorial Committee of the Colloquium Publications, Professor Oswald Veblen.

Member of the Editorial Board of the American Journal of Mathematics, Professor E. W. Chittenden.

Members of the Council, Professors G. D. Birkhoff, G. A. Bliss, L. M. Graves, Einar Hille, and G. Y. Rainich, to serve three years.

Members of the Board of Trustees, Professors L. P. Eisenhart, W. B. Fite, Dr. Robert Henderson, Professors G. W. Mullins, and R. G. D. Richardson, to serve two years.

The reports of the Treasurer and of the auditors (Professor H. W. Reddick and Mr. J. J. Tanzola) showed a balance of $\$ 3771.93$, exclusive of the balances in the Bulletin, Transactions, Colloquium, Journal, Library, Sinking Fund and special funds. The Society's Endowment Fund, invested in securities of par value $\$ 77,000$, yielded in 1932 a net income of $\$ 3544.16$; sustaining memberships for the year amounted to $\$ 1700$. The 
amount received from sales of the Society's publications was $\$ 7756.17$. During the year special contributions from members were received to the amount of $\$ 1032.09$. The trustees adopted a budget for 1933 showing estimated expenditures and receipts as $\$ 35,559.25$ and $\$ 35,239.25$ respectively. The Librarian reported that the Library of the Society now contains 7800 volumes.

The following appointments were reported: as tellers for the election at the annual meeting, Dr. J. L. Doob, Dr. J. M. Feld, and Professor C. O. Oakley; as representative on the National Research Council for the period beginning July 1, 1933, and to succeed Professor D. R. Curtiss, Professor R. G. D. Richardson; as the committee on nomination of the Gibbs Lecturer for 1934, Professors L. P. Eisenhart (chairman), E. T. Bell, and R. D. Carmichael; as representatives on the Council of the American Association for the Advancement of Science, Professors Louis Ingold and $\mathrm{M}$. H. Ingraham; as the nominating committee, Professors Dunham Jackson (chairman), G. D. Birkhoff, Dr. T. C. Fry, Professors R. L. Moore, and W. L. G. Williams; to represent the Society at the dedication of the Mary Reed Library of the University of Denver, October 28, 1932, Professor A. J. Kempner.

It was announced that Professor Norbert Wiener had accepted the invitation to give the New Haven Colloquium and that his subject is tentatively chosen to be Analytic properties of characters of Abelian groups.

Future meetings of the Society were announced as follows: New York, February 25, April 14-15, October 28; Stanford University, March 18; Chicago, April 14-15, June 19-24; Pasadena, December 2; Cambridge, December 26-30.

It was announced that the invitation from the University of Pittsburgh and Carnegie Institute of Technology to hold the Annual Meeting of 1934 in Pittsburgh in connection with the meetings of the A.A.A.S. had been accepted.

The Secretary reported that at the request of the group on the Pacific Coast, Professor B. A. Bernstein had been appointed to act as Secretary in place of Dean T. M. Putnam, who is on leave of absence, during the period January 1-August 15, 1933.

It was announced that for the year 1933 the Transactions 
would give fifty free reprints to authors instead of twenty-five.

Professors Harry Bateman, G. D. Birkhoff, and J. F. Ritt were reappointed for a period of three years, 1933-35, as representatives of the Society on the editorial board of the Annals of Mathematics.

The papers whose titles appear below were read in five sections. Professor G. D. Birkhoff presided at the section on Analysis on Tuesday evening (papers numbered 1 to 23), and Professor A. B. Coble at the section on Algebra (papers numbered 24 to 34). At the joint session on Wednesday afternoon VicePresident H. H. Mitchell presided. On Thursday morning Professors D. C. Gillespie and Tomlinson Fort presided at the section on Analysis and Applications (papers numbered 35 to 51), and President L. P. Eisenhart and Professor A. B. Coble at the section on Geometry, Foundations, and Point Sets (papers numbered 52 to 66). Presidents Eisenhart and Coble presided at the general session on Thursday afternoon (papers numbered 67 to 73), and Professor Birkhoff at the Josiah Willard Gibbs Lecture which followed. At the Princeton session Professor Oswald Veblen presided. Mr. Joseph Lev was introduced by Professor D. C. Gillespie, Dr. Frances T. Cope by Professor T. F. Cope, Miss Griffin by Professor J. M. Thomas, Mr. Blumberg by Professor J. S. Taylor, Miss Van Hook by Professor H. R. Brahana, Mr. Knipp by Professor F. A. Foraker, and Miss Lawrence by Professor Edward Kasner. The papers whose abstract numbers are followed by the letter $t$ were read by title.

1. The effects of linear transformations on the divergence of bounded sequences and functions, by Mr. Joseph Lev. (Abstract No. 38-11-290.)

2. Infinite systems of differential equations with applications to partial differential equations, by Dr. D. C. Lewis, Jr. (Abstract No. 39-1-1.)

3. Concerning the double Poisson integral and its derivatives, by Dr. C. E. Rhodes. (Abstract No. 39-1-2.)

4. Newtonian potentials as functionals of the masses, by Dr. Mildred M. Sullivan. (Abstract No. 39-1-3.)

5. An analytic criterion that a surface possess finite Lebesgue area, by Dr. C. B. Morrey, Jr. (National Research Fellow). (Abstract No. 39-1-64.)

6. On equations in mixed differences, Part III, by Mr. L. B. Robinson. (Abstract No. 39-1-5.) 
7. Some applications of Murphy's theorem, by Professor Harry Bateman. (Abstract No. 39-1-6-t.)

8. The fundamental theorems on second-order cross partial derivatives, by Dr. A. E. Currier. (Abstract No. 38-7-172-t.)

9. Concerning the uniqueness of solution curves of $d y / d x$ $=f(x, y)$, by Professor F. R. Bamforth and Mr. H. H. Alden. (Abstract No. 39-1-7-t.)

10. Formal solutions of irregular linear differential equations, by Dr. Frances T. Cope. (Abstract No. 39-1-8-t.)

11. The length of closed level curves of a harmonic function, by Dr. C. H. Dix. (Abstract No. 39-1-9-t.)

12. On the existence of the absolute minimum in problems of Lagrange, by Professor L. M. Graves. (Abstract No. 39-1-10-t.)

13. On minimizing the quotient of two definite integrals, by Professor E. L. Mackie. (Abstract No. 39-1-11-t.)

14. Summability for absolutely convergent series, by Professor Florence M. Mears. (Abstract No. 39-1-12-t.)

15. An extension of Leibnitz's formula for product-differentiation to differentiation and integration for all real orders, by Professor I. M. Sheffer. (Abstract No. 39-1-13-t.)

16. On the summability of derived series of the Fourier-Lebesgue type, by Dr. A. H. Smith. (Abstract No. 39-1-14-t.)

17. A theory of quasi-analytic classes, by Dr. W. J. Trjitzinsky. (Abstract No. 39-1-4-t.)

18. The general case of integro-q-difference equations, by Dr. W. J. Trjitzinsky. (Abstract No. 39-1-15-t.)

19. On approximation by non-vanishing analytic functions, by Professor J. L. Walsh. (Abstract No. 38-11-292-t.)

20. Invariants of Pfaffian systems, by Miss Mabel Griffin. (Abstract No. 39-1-16-t.)

21. Expansions according to a given system of functions, by Mr. Y. Y. Tseng (Fellow of the Chinese Government). (Abstract No. 39-1-17-t.)

22. The characteristic value problem of Hermitian functional operators in a non-Hilbertian space, by Mr. Y. Y. Tseng (Fellow of the Chinese Government). (Abstract No. 39-1-18-t.)

23. A generalized sampling distribution for the multiple correlation coefficient, by Dr. S. S. Wilks (International Research Fellow). (Abstract No. 39-1-19-t.)

24. On the parametric representation of orthogonal and unitary 
square matrices, by Professor F. D. Murnaghan. (Abstract No. 39-1-20.)

25. On quasi-commutative matrices, by Professor N. H. McCoy. (Abstract No. 38-11-291.)

26. On a theorem of higher reciprocity for polynomials in a Galois field, by Professor Leonard Carlitz. (Abstract No. 391-21.)

27. The Jacobian algorithm for periodic continued fractions as defining a cubic irrationality, by Professor J. B. Coleman. (Abstract No. 39-1-23.)

28. The transformations effecting the reduction of positive quaternary quadratic forms, by Professor B. W. Jones. (Abstract No. 39-1-24.)

29. Pseudo-transitivity in finite and infinite groups (preliminary report), by Dr. S. L. Robinson (National Research Fellow). (Abstract No. 39-1-57.)

30. Properties of a certain type of continued fractions, by $\mathrm{Mr}$. J. O. Blumberg. (Abstract No. 39-1-22-t.)

31. Some formulas in additive arithmetic, by Professor Leonard Carlitz. (Abstract No. 39-1-25-t.)

32. On Waring's problem for odd powers, by Dr. R. D. James (National Research Fellow). (Abstract No. 39-1-26-t.)

33. Pairs of generators of groups of degree not greater than eight, by Miss Clarice Van Hook. (Abstract No. 39-1-27-t.)

34. On the class numbers of a cyclic field and a sub-field, by Professor C. G. Latimer. (Abstract No. 39-1-28-t.)

35. A step-polygon of a denumerable infinity of sides which bounds no finite area, by Professors Jesse Douglas and Philip Franklin. (Abstract No. 39-1-29.)

36. On the summation of infinite series, by Professor A. J. Kempner. (Abstract No. 39-1-30.)

37. The potential transformation, by Professor H. B. Phillips. (Abstract No. 39-1-31.)

38. An aspect of the theory of linear differential equations, by Professor I. M. Sheffer. (Abstract No. 39-1-32.)

39. On linear operations in linear metric spaces, by Dr. I. J. Schoenberg and Dr. Wladimir Seidel. (Abstract No. 39-1-33.)

40. On the continued fractions associated with, and corresponding to, $\int_{a}^{b}[p(y) /(x-y)] d y$, by Professor J. A. Shohat. (Abstract No. 39-1-34.)

41. Analytic extensions of differentiable functions defined on 
closed sets, by Dr. Hassler Whitney (National Research Fellow). (Abstract No. 39-1-35.)

42. The ellipsoidal viscosity distribution function, by Professor W. S. Kimball. (Abstract No. 39-1-36.)

43. On the Strömgren-Wintner natural termination principle, by Dr. G. B. Price. (Abstract No. 39-1-37.)

44. Interpolation with rationally centered frequencies, by Professor C. H. Forsyth. (Abstract No. 39-1-38.)

45. Almost periodic transformations, by Mr. R. H. Cameron. (Abstract No. 38-11-289.)

46. Subharmonic functions and minimal surfaces, by Professor Tibor Radó and Dr. E. F. Beckenbach (National Research Fellow). (Abstract No. 39-1-56.)

47. Concerning spaces without local cut points, by Dr. C. H. Harry. (Abstract No. 39-1-58.)

48. The skewness and kurtosis of observations, by Professor P. R. Rider. (Abstract No. 39-1-61-t.)

49. Note on a preceding paper, by Dr. W. T. Reid. (Abstract No. 39-1-59-t.)

50. Analogues of the Jacobi condition for the problem of Mayer in the calculus of variations, by Dr. W. T. Reid. (Abstract No. 39-1-60-t.)

51. Linear integral equations of functions of two variables, by Dr. T. S. Peterson. (Abstract No. 39-1-62-t.)

52. Some involutorial line transformations, by Mr. J. M. Clarkson. (Abstract No. 39-1-39.)

53. The general web of surfaces and the involution defined by it, by Professor T. R. Hollcroft. (Abstract No. 39-1-40.)

54. Certain relations between the Frégier curve and the evolute, by Mr. J. C. Knipp. (Abstract No. 39-1-41.)

55. On the Segre curved four-space representation of the plane of two complex variables, by Dr. A. E. Staniland. (Abstract No. 39-1-43.)

56. Polyhedral approximations to regular topological $n$-manifolds, by Dr. S. S. Cairns. (Abstract No. 39-1-44.)

57. Special types of higher dimensional closed sets, by Dr. P. M. Swingle (National Research Fellow). (Abstract No. 39-1-45.)

58. On the existence of totally imperfect and punctiform connected subsets in a given continuum, by Dr. G. T. Whyburn. (Abstract No. 38-11-293.) 
59. Plane quartic curves in the Galois fields of order $2^{n}$, by Professor A. D. Campbell. (Abstract No. 38-11-295-t.)

60. Cremona involutions defined by a pencil of cubic surfaces, by Professor Evelyn Carroll Rusk. (Abstract No. 39-1-42-t.)

61. On the Kasner ratio curves, by Miss Lucile Lawrence. (Abstract No. 39-1-63-t.)

62. Determinantal theory of d-cyclic and pseudo d-cyclic sets of points (preliminary report), by Dr. L. M. Blumenthal and Mr. G. A. Garrett. (Abstract No. 39-1-46-t.)

63. On complete independence of certain sets of postulates for fields, by Professor N. H. McCoy. (Abstract No. 39-1-47-t.)

64. Characterizations of certain curves by continuous functions defined upon them, by Dr. G. T. Whyburn. (Abstract No. 38-11294-t.)

65. Recurrent geodesics on any closed orientable surface of genus one, by Dr. G. A. Hedlund. (Abstract No. 39-1-48-t.)

66. Non-conjugate osculating quadrics of a curve on a surface, by Professor R. C. Bullock. (Abstract No. 39-1-49-t.)

67. On a series of Cremona involutions defined by a pencil of ruled surfaces, by Professor Virgil Snyder. (Abstract No. 3811-273.)

68. The convergence of some non-linear processes of approximation, by Professor Dunham Jackson. (Abstract No. 39-1-50.)

69. Note on Poincarê's sweeping out process, by Professor G. C. Evans. (Abstract No. 39-1-51.)

70. The tensor form of boundary problems in the calculus of variations, by Professor Marston Morse. (Abstract No. 391-52.)

71. Exceptional sets, by Professor Henry Blumberg. (Abstract No. 39-1-53.)

72. The inversion of the Laplace integral and the related moment problem, by Professor D. V. Widder. (Abstract No. 39-1-55.)

73. An alternating process in the problem of Plateau, by Professor Tibor Radó. (Abstract No. 39-1-54-t.)

R. G. D. Richardson, Secretary 